\title{
Cognitive performance in children and adolescents at high-risk for obsessive- compulsive disorder
}

\author{
Elisa Teixeira Bernardes ${ }^{1 *} \mathbb{D}$, Leonardo Cardoso Saraiva ${ }^{1 \dagger}$, Marina de Marco e Souza ${ }^{1}$, Marcelo Queiroz Hoexter ${ }^{1}$, \\ Priscila Chacon', Guaraci Requena², Euripedes Constantino Miguel', Roseli Gedanke Shavitt ${ }^{1}$, \\ Guilherme Vanoni Polanczyk ${ }^{1}$, Carolina Cappi ${ }^{1}$ and Marcelo Camargo Batistuzzo ${ }^{1,3}$
}

\begin{abstract}
Background: Cognitive performance has been studied in adults with obsessive-compulsive symptoms (OCS) and in adult relatives of patients with obsessive-compulsive disorder (OCD) Meanwhile, few studies have been conducted with children under the same conditions. This study compared the neurocognitive domains previously associated with dysfunction in OCD, especially visuoconstructive ability, visuospatial memory, executive functions, and intelligence, in children and adolescents at high risk (HR) for OCD $(n=18)$ and non-OCD controls (NOC) $(n=31)$.

Methods: For the HR group, we considered the first-degree relatives of patients with OCD that present OCS, but do not meet diagnostic criteria for OCD. Psychiatric diagnosis was assessed by experienced clinicians using the Structured Clinical Interview for DSM-IV and OCS severity was measured by the Yale-Brown Obsessive-Compulsive Scale. Neurocognitive assessment was performed with a comprehensive neuropsychological battery. Performance on the cognitive domains was compared between groups using Multivariate Analysis of Variance, whereas performance on the neuropsychological variables was compared between groups using independent t-tests in a cognitive subdomain analysis.

Results: The cognitive domain analysis revealed a trend towards significance for impairments in the motor and processing speed domain $(p=0.019 ; F=3.12)$ in the HR group. Moreover, the cognitive subdomain analysis identified a statistically significant underperformance in spatial working memory in the HR group when compared to the NOC group $(p=0.005 ; t=-2.94)$, and a trend towards significance for impairments in non-verbal memory and visuoconstructive tasks in the HR group.

Conclusions: Our results suggest impairments in spatial working memory and motor and processing speed in a non-clinical sample of HR participants. Considering the preliminary nature of our findings, further studies investigating these neurocognitive domains as potential predictors of pediatric OCD are warranted.
\end{abstract}

Keywords: Obsessive-compulsive symptoms, High-risk, Obsessive-compulsive disorder, First degree relatives, Neuropsychological assessment, Cognitive functions

\footnotetext{
* Correspondence: elisa.t.bernardes@gmail.com

'Elisa Teixeira Bernardes and Leonardo Cardoso Saraiva shared co-first authorship, both have contributed equally.

'Departamento de Psiquiatria, Hospital das Clinicas HCFMUSP, Faculdade de Medicina, Universidade de Sao Paulo, R. Dr Ovidio Pires de Campos, 875, Sao Paulo, SP, Brazil

Full list of author information is available at the end of the article
}

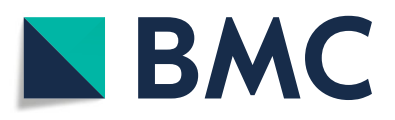

(- The Author(s). 2020 Open Access This article is licensed under a Creative Commons Attribution 4.0 International License, which permits use, sharing, adaptation, distribution and reproduction in any medium or format, as long as you give appropriate credit to the original author(s) and the source, provide a link to the Creative Commons licence, and indicate if changes were made. The images or other third party material in this article are included in the article's Creative Commons licence, unless indicated otherwise in a credit line to the material. If material is not included in the article's Creative Commons licence and your intended use is not permitted by statutory regulation or exceeds the permitted use, you will need to obtain permission directly from the copyright holder. To view a copy of this licence, visit http://creativecommons.org/licenses/by/4.0/. The Creative Commons Public Domain Dedication waiver (http://creativecommons.org/publicdomain/zero/1.0/) applies to the data made available in this article, unless otherwise stated in a credit line to the data. 


\section{Background}

Obsessive-compulsive disorder (OCD) is a neuropsychiatric disorder characterized by intrusive thoughts (obsessions) and repetitive behaviors (compulsions) [1]. With a lifetime prevalence of $1.5-2.5 \%$ [2, 3], OCD constitutes a common disorder which onset typically occurs during childhood or early adulthood [4] and that presents two peaks of onset, being the first one during preadolescent childhood (around eleven years) and the other around late adolescence and early adulthood [5]. Current pharmacological and psychotherapeutic treatments can benefit $60-70 \%$ of patients $[6,7]$ and treatmentrefractory disease is common $[8,9]$. In addition, untreated OCD usually persists and becomes chronic [10]. As such, further investigations are warranted for advances in OCD care and prevention.

Consistent with its genetic underpinnings [11], several family studies have demonstrated that first-degree relatives (FDRs) of individuals with OCD are at an increased risk for developing the disorder $[12,13]$. In addition, diverse genetic approaches have indicated that subclinical OCD and the full-blown disorder share a considerably similar genetic predisposition $[14,15]$. Since subclinical OCD can portend the full-blown disorder in children and adolescents, especially those with greater genetic susceptibility [16], the discovery of markers of vulnerability to OCD in this high-risk population could lead to the development of novel approaches for early detection and management of susceptibility to OCD in the pediatric population. Such approaches would, therefore, improve OCD prevention.

Impairment in multiple cognitive functions has been consistently reported among patients with OCD [17]. Underperformance in the intelligence quotient (IQ) has been demonstrated in adult OCD, with more severe deficits in performance IQ as compared to verbal IQ [18]. Moreover, deficits in visuospatial abilities, executive functions, verbal memory, verbal fluency, and attention have been reported in adults with OCD [19]. Given the genetic nature of the disorder, putative impairment in several cognitive functions has been extensively investigated in unaffected FDRs of individuals with OCD [20-27]. Consistently, deficits in inhibitory control [21, 22], decision making [23, 24], long-term verbal and visual memories [25], planning [26], working memory, verbal fluency and motor speed [27] have been found in adult FDRs of individuals with OCD. Considering the contribution of genetic factors in the etiology of early-onset OCD [28], impaired inhibitory control and cognitive flexibility were recently reported for an adult sample of earlyonset OCD patients and their unaffected FDRs [29].

Cognitive function has been less extensively investigated in pediatric OCD when compared to adult OCD
[30], which could account for the inconsistency of findings reported in previous studies. Indeed, a metaanalysis revealed no significant impairments in cognitive functions associated with pediatric OCD, possibly due to the small number of studies included [31]. Conversely, deficits in visual memory, visual organization, processing speed, cognitive flexibility, and planning have been reported for pediatric OCD [30, 32-34]. Moreover, the assessment of cognitive function in pediatric FDRs of individuals with OCD has been largely unexplored. To our knowledge, only one study so far has assessed the cognitive performance of pediatric patients with OCD, their unaffected FDRs, and healthy individuals [34]. Both patients with OCD and their FDRs exhibited underperformance in planning tasks. Such findings warrant further investigations of the cognitive function in pediatric FDRs of individuals with OCD.

Furthermore, research has been conducted on the association between cognitive dysfunction and subclinical OCD. Previous investigations have not found neuropsychological deficits among adults with obsessivecompulsive symptoms (OCS) [35, 36], notwithstanding preliminary evidence supports an association between cognitive function and OCS among children. For instance, response inhibition and set-shifting have been shown to predict OCS in children younger than six-years-old, and response inhibition has been shown to predict OCS in children older than six-years-old [37]. Such findings suggest that cognitive impairment is associated with subclinical pediatric OCD. Considering the combined evidence of cognitive impairment in pediatric FDRs of individuals with OCD and in pediatric individuals manifesting subclinical OCD, the investigation of cognitive dysfunction as a marker of vulnerability to OCD in children and adolescents may enhance OCD prevention.

Therefore, in the present study, our aim was to assess the cognitive performance of pediatric individuals at high risk (HR) for OCD in comparison to non-OCD controls (NOC). Accordingly, we defined the presence of subclinical OCD and being an FDR of a patient with OCD as the criteria for the inclusion of pediatric participants in the HR group. To our knowledge, the present study is the first to investigate cognitive functioning in pediatric FDRs with subclinical OCD.

\section{Method}

\section{Design and recruitment}

As part of the ongoing projects conducted by the $\mathrm{Na}$ tional Institute of Developmental Psychiatry for Children and Adolescents [14, 38], the present cross-sectional study was conducted in a pediatric sample of $18 \mathrm{HR}$ and 31 NOC (see flowchart in the supplementary files for details). The participants were recruited through media advertisements and an active search conducted at private 
and public schools. The inclusion criteria for the HR group were: 1) age between 7 and 18 years; 2) being a first-degree relative (sibling or offspring) of an individual with OCD; 3) presenting OCS; 4) not meeting diagnostic criteria for OCD and 5) not having undergone or currently undergoing any sort of psychiatric treatment. The exclusion criteria for the HR group were: 1) history of head injury; 2) history of substance abuse; 3) presence of intellectual disability or any other neuropsychiatric diagnosis; 4) the presence of any neurological condition and 5) pregnancy or lactation. Apart from being a first-degree relative of an individual with OCD and presenting OCS, the inclusion and exclusion criteria for the NOC group were similar to the aforementioned criteria.

Diagnostic assessments to confirm OCD status and assess other comorbidities were conducted by experienced clinicians using the Structured Clinical Interview for DSM-IV (SCID-I) [39]. Once the OCD participants were confirmed to meet study criteria and after permission, we contacted the first relatives (siblings and offspring) of the participants. For assessment of psychiatric diagnosis among the FDRs, the SCID-I was administered for adults and the Kiddie Schedule for Affective Disorders and Schizophrenia [40] was administered for pediatric individuals. The Yale-Brown Obsessive-Compulsive Scale (Y-BOCS) [41] was used for measuring the severity of OCS. Additionally, the Petersen Puberty Scale [42] and the Edinburgh Handedness Inventory [43] were administered to ascertain the pubertal status of pediatric participants and their handedness, respectively.

\section{Neuropsychological assessment}

The neuropsychological battery comprised tests that assessed the following cognitive domains: intelligence, attention, motor and processing speed, visuoconstructive abilities, verbal and visuospatial memories, working memory, cognitive flexibility, and inhibitory control. The neuropsychological tests administered and cognitive domains are outlined in Tables 1 and 2, respectively. The neuropsychological tests were administered by experienced psychologists in sessions which duration on average lasted ninety minutes. No issues in terms of fatigue or cooperation from the part of the participants were reported for those sessions.

\section{Ethical considerations}

This study was approved by the Medical Ethics Committee of the Faculty of Medicine at the University of Sao Paulo. All participants and their respective parents or legal guardians were informed about the procedures pertaining to the study and provided their written informed consent prior to enrollment of the participants in the study.

\section{Data analysis}

Demographic and clinical variables were analyzed using the independent samples $t$-test for continuous variables and the Chi-squared test for categorical variables. Normality assumptions of neuropsychological variables were evaluated using the Shapiro-Wilk test. Violations of the normality assumptions were assessed according to the statistical significance threshold ( $p$-value) set at 0.01 . In the cases of non-normal distribution, a correction was applied using the 'bestNormalize' function of RStudio (package 'bestNormalize'). After that, the normality of the variables was reassessed.

The neuropsychological variables were analyzed at the domain and the subdomain levels. In an initial analysis at the domain level, neuropsychological variables were grouped as follows: intelligence, attention, motor and processing speed, visuoconstructive abilities, visuospatial memory, verbal memory, working memory, cognitive flexibility, and inhibitory control. The global performance on each cognitive domain was compared between the groups using the Multivariate Analysis of Variance (MANOVA) ( $\mathrm{R}$ package 'stats', function 'manova'). Moreover, a further analysis was conducted at the subdomain level, whereby performance on the neuropsychological variables within each domain was compared between the groups using the independent samples $t$ test ( $\mathrm{R}$ package 'stats', function 't.test'). Additionally, effect sizes (Cohen's d) for each between-group comparison were also computed ( $\mathrm{R}$ package 'lsr', function 'cohen'). After group comparisons, a post-hoc power calculation analysis was performed for the cognitive subdomain analysis. The Bonferroni correction was applied to all analyses conducted considering the number of cognitive domains assessed, as in Purcell and colleagues [55]. As such, a stricter statistical significance threshold was set at $p=0.0055(0.05 / 9)$. Considering the exploratory nature of this study, $p$ values between 0.05 and 0.0055 were considered as a trend towards significance, which is referred as nominal significance from this point onwards. Statistical analyses were performed using the RStudio, version 1.2.1335 (2019).

\section{Results}

\section{Demographic and clinical variables}

No statistically differences between the groups were found in terms of sex, pubertal development, handedness, years of education, and total IQ (Table 3). Both groups presented total IQ scores in the normal range. As measured by the Y-BOCS, the severity of OCS in the HR group was below the clinical range.

\section{Cognitive domains analysis}

The cognitive domain analysis revealed that the HR group exhibited a nominally significant overall 
Table 1 Neuropsychological Tests Administered in the Study

\begin{tabular}{ll}
\hline Name & Definition \\
\hline Wechsler Abbreviated Scale of Intelligence & Estimates a total IQ score, which is further partitioned into verbal and performance IQ scores. \\
(WASI) $[44,45]$ & Verbal IQ: \\
& Vocabulary: the participant needs to define the meaning of certain words. \\
& Similarities: the participant must ascertain the similarities between two words. \\
& Performance IQ: \\
Block Design: requires the participant to assemble colored blocks into two-color figures. & Matrix Reasoning: the participant has to complete a geometric pattern by selecting the \\
best-fitting picture out of a set of pictures.
\end{tabular}

Rey Auditory Verbal Learning Test (RAVLT) [46]

Trail-Making Test (TMT) - [47]

Design Fluency Test (DFT) - [47]

Color and Word Interference Test (CWIT) - [47]

Wisconsin Card Sorting Test (WCST) [48]

Go/NoGo task [49]

\section{Grooved Pegboard Task \\ [50]}

Rey-Osterrieth Complex Figure (ROCF) [51]

Corsi Block-Tapping Test (CBTT) - Wechsler Memory Scale (WMS-R) [52]

Digit Span Test (DST) - Wechsler Intelligence Scale for Children - Third Edition [53]

Brixton Test - [54]
A word-list with 15 items repeated 5 times. In each repetition, the subject needs to recall the maximum number of words. There is also an interference 15-word list and a delayed recall, after 30 min.

This paradigm comprises five conditions:

1) visual scanning: visual cancellation task.

2) number sequencing: connect the dots, using a numerical sequence.

3) letter sequencing: connect the letters, in an alphabetical sequence.

4) number-letter switching: connect dots, using numbers and letters in a numerical and alphabetical sequence.

5) motor speed: connect filled circles based on a dotted trail.

This test comprises three conditions, in each the participant needs to create as many designs as possible in a limited time:

1) Filled dots: connecting filled/black dots.

2) Empty dots: connecting empty/white dots.

3) Switching: connecting filled and empty dots.

This task comprises four conditions, which need to be completed as quickly as possible: 1) Condition 1: A set of colors is shown and the participant needs to name the colors.

2) Condition 2: A set of names of colors printed in black are shown and the participant needs to read the words.

3) Condition 3: A set of color names is printed in different colors (ex: "blue" printed in pink) and the participant needs to inhibit the tendency to read the words, and then voice the names of the colors in which the words are printed.

4) Condition 4: A set of colors names is printed outside and inside a rectangle and the participant needs to read the names of the colors when they are inside the rectangle and to voice the colors in which the words are printed when they are outside a rectangle.

WCST is a classic executive functioning test in which the subject has to combine cards following a specific rule that he does not know (color, geometric form, or number) and for each trial, the subject receives feedback saying if the match is right or wrong.

It consists of a computerized test, built on a homemade paradigm (E-Prime) The participant has to press the spacebar whenever a letter can be seen on the computer screen, as quickly as possible (condition "Go"). Alternatively, during the "NoGo" conditions, the participant was required to press different keyboard keys according to the colors of a letter presented on a computer screen. The condition "NoGo" is composed of specific letters in specific colors ('O' in blue or ' $\mathrm{E}$ ' in pink). There are a total of 96 trials: 72 "Go" and 24 "NoGo".

This test comprises two conditions, in each the participant has to use only one hand to fill twenty-five holes with pegs in a predetermined order, as quickly as possible.

It consists of a visuospatial task in which the subject needs to copy a complex and detailed geometrical figure, and recall it without seeing it again, after 3 and after $30 \mathrm{~min}$.

This test comprises forward and backward conditions. In the forward condition, the participant observes the examiner taping a set of blocks in a particular sequence, and then is required to tap the blocks in the exact same sequence. The backward condition follows a similar paradigm, with the exception that the participant is required to tap the blocks in the inverse sequence.

It consists of a verbal paradigm which also comprises forward and backward conditions. In the DST, the participant is required to listen to a numeric sequence and repeat the sequence in the same and inverse orders during the forward and backward conditions, respectively.

It requires the participant to predict the position of a circle based on its previous positions. underperformance in tasks measuring the motor and processing speed abilities ( $p=0.019 ; \mathrm{F}=3.115)$ (Fig. 1a). No statistically or nominally significant difference in overall performance was found for the other cognitive domains (Table 4). Only the scores in the immediate recall condition of the ROCF paradigm were removed 
Table 2 Neuropsychological Domains and Tests Evaluated in the Study

\begin{tabular}{l} 
Domain Definition \\
\hline Intelligence \\
General intelligence (IQ) \\
Attention \\
Endogenous processing of selecting relevant stimuli (concentrating) in the \\
environment (e.g., objects) $^{\mathrm{a}}$
\end{tabular}

\section{Motor and processing speed}

Ability to quickly process information and execute it (fine motor skills)

\section{Visuoconstructive abilities}

Coordination of fine motor skills with spatial abilities

\section{Visuospatial memory}

Memory for visual and spatial information

\section{Verbal memory}

Memory for verbal information

\section{Working memory}

Ability to retain information and perform mental operations from them

\section{Cognitive flexibility}

Ability to change the perspectives, thinking of new possibilities for solving a problem
Subtest variables

Wechsler abbreviated scale of intelligence (WASI) [44, 45]

Block Design; Matrix; Vocabulary; and Similarities.

Rey auditory verbal learning test (RAVLT) [46]

Span A; Span B

Trail making test (TMT) - Delis-Kaplan executive function scale (D-KEFS) [47]

$1^{\text {st }}$ condition omissions; and $4^{\text {th }}$ condition sequence errors

Design fluency test (DFT) - D-KEFS [47]

DFT 1 and 2 - \% errors

Wisconsin card sorting test (WCST) [48]

WCST failures to maintain set.

Go/NoGo [49]

Go/NoGo omissions.

Color-word interference test (CWIT) - D-KEFS [47]

Color naming time (CWIT 1); and word reading time (CWIT 2)

Grooved pegboard test [50]

Dominant hand time; and non-dominant hand time

TMT - D-KEFS [47]

$5^{\text {th }}$ condition time

Block Design test - WASI [44, 45]

Rey-Osterrieth complex figure (ROCF) [51]

Copy total score

Corsi block-tapping test (CBTT) - Wechsler Memory Scale

(WMS-R) [52]

Forward hits

ROCF [51]

Immediate recall; and Delayed recall

Digit span test (DST) - Wechsler Intelligence Scale for Children (WISC-III) [53]

Forward hits

Rey auditory verbal learning test (RAVLT) [46]

Immediate recall; and delayed recall

DST - WISC-III [53]

Backward hits

CBTT - WMS-R [52]

Backward hits

WCST [48]

Perseverative errors; and categories

DFT - D-KEFS [47]

DFT 3 - \% perseverative responses

Brixton [54]

Brixton hits

TMT - D-KEFS [47]

$4^{\text {th }}-5^{\text {th }}$ condition time difference

Go/NoGo - commission errors

CWIT - D-KEFS [47]

CWIT 3 errors; CWIT 4 errors; and CWIT 3-1 time difference

\section{Inhibitory control}

Ability to resist an inclination to perform an action and, opting for a more convenient one

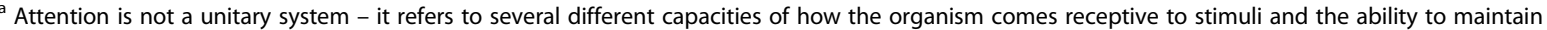
concentration focused on stimuli over time (sustained attention). WASI - Wechsler abbreviated scale of intelligence; TMT - Trail making test; D-KEFS - DelisKaplan executive function scale, DTF - Design fluency test; WCST - Wisconsin card sorting test; CWIT - Color-word interference test; CBTT - Corsi block-tapping test; WMS - Wechsler Memory Scale; ROCF - Rey-Osterrieth complex figure; DST - Digit span test; WISC III - Wechsler Intelligence Scale for Children 3rd edition; RAVLT - Rey auditory verbal learning test
\end{abstract}


from the cognitive domain analysis due to multicollinearity $(r>0.9)$.

\section{Cognitive subdomain analysis}

Means and standard deviations for each of the neuropsychological variables are displayed in Table 5. The cognitive subdomain analysis revealed that the difference between the groups in the number of correct taps in the forward condition of the Corsi Block Tapping Test was statistically significant after the Bonferroni correction $[\mathrm{t}$ $(45)=-2.94, p=0.0050, \mathrm{~d}=0.79]$ (Fig. 1b). In addition, group-differences in the following outcome variables achieved nominal significance: the number of correct taps in the backward condition of the Corsi Block Tapping Test [ $\mathrm{t}(44)=-2.31, p=0.0260, \mathrm{~d}=0.67]$, the time to complete the fifth condition of the Trail Making Test [t $(28)=2.27, p=0.0301, \mathrm{~d}=0.69]$, the scores in the Block Design subtest [ $\mathrm{t}(43)=-2.08, p=0.042, \mathrm{~d}=0.57$ ] and the discrepancy between the scores of verbal IQ and performance IQ [t $(29)=2.11, p=0.043, \mathrm{~d}=0.66$ ]. No statistically or nominally significant difference between the groups in other outcome variables was found. A secondary subdomain analysis was performed to compare the neuropsychological variables between the groups adjusting for sex and age, which revealed results in the same direction as those obtained in the comparison using independent t-tests (data not shown). A power analysis conducted after the group comparisons revealed that the cognitive subdomain analysis had $80 \%$ power to detect group differences with Cohen`s $\mathrm{d}=0.75$ and $37.65 \%$ power to detect group differences with Cohen`s $\mathrm{d}=0.4$, in both cases considering alpha $=0.05$ (onetailed).

\section{Discussion}

The purpose of this study was to investigate the cognitive performance of pediatric individuals at HR for OCD in comparison to NOC control pediatric individuals. At the cognitive domain level, our analyses revealed nominally significant motor and processing speed impairments in the HR group as compared to the NOC group. On the other hand, at the subdomain level, we observed spatial working memory deficits in the HR group and nominally significant impairments in non-verbal memory and visuoconstructive tasks in the HR group.

Previous studies evaluating adults with OCD have consistently reported impairments in processing speed [5661], which have also been reported for adult FDRs of patients with OCD [27]. Likewise, the assessment of neuropsychological function in the largest pediatric sample to date identified significant underperformance in tasks measuring processing speed among patients with OCD, in comparison to individuals who do not have the disorder [30]. Moreover, deficits in this cognitive domain have been associated with ordering and symmetry symptoms manifested by youth with OCD [62]. Since treatment response has been shown to improve the deficits in processing speed among both pediatric [63] and adult patients $[64,65]$ with $\mathrm{OCD}$, it could be hypothesized that impairments in this cognitive domain represent a modifiable vulnerability marker for OCD across the lifetime. In this sense, a study reported that pathological uncertainty in adult OCD patients underlies deficits in processing speed [66], which suggests that behavioral interventions could improve processing speed skills and consequently benefit children and adolescents at higher risk for the disorder. Consistent with the transdiagnostic etiologies of psychiatric disorders [67, 68], deficits in

Table 3 Demographic and clinical characteristics of the high-risk and non-OCD control individuals

\begin{tabular}{|c|c|c|c|}
\hline & High-Risk $(\mathrm{n}=18)$ & Non-OCD Control $(n=31)$ & $p$-value \\
\hline & $\mathrm{n}(\%) / \mathrm{M}(\mathrm{SD})$ & $\mathrm{n}(\%) / \mathrm{M}(\mathrm{SD})$ & \\
\hline \multicolumn{4}{|l|}{ Sex } \\
\hline Male & $12(66 \%)$ & $18(58 \%)$ & $0.551^{a}$ \\
\hline \multicolumn{4}{|l|}{ Puberty Development } \\
\hline Age & $11.1(2.4)$ & $11.7(1.9)$ & $0.365^{b}$ \\
\hline \multicolumn{4}{|l|}{ Handedness } \\
\hline Right & 16 (89\%) & $30(96.8 \%)$ & $0.377^{a}$ \\
\hline \multicolumn{4}{|l|}{ Education Level } \\
\hline Years of Education & $6.1(2.5)$ & $6.3(2.1)$ & $0.743^{b}$ \\
\hline Total IQ & $103.5(12.2)$ & $105.6(13.5)$ & $0.592^{b}$ \\
\hline \multicolumn{4}{|l|}{ Y-BOCS } \\
\hline Total & $7.1(5.3)$ & - & - \\
\hline Obsessions & $3.6(2.6)$ & - & - \\
\hline Compulsions & $3.5(2.9)$ & - & - \\
\hline
\end{tabular}

a Chi-squared Test $\backslash^{\mathrm{b}}$ Independent t-test. M - mean; SD - standard deviation; IQ - Intelligence quotient; Y-BOCS - Yale-Brown Obsessive Compulsive Scale 

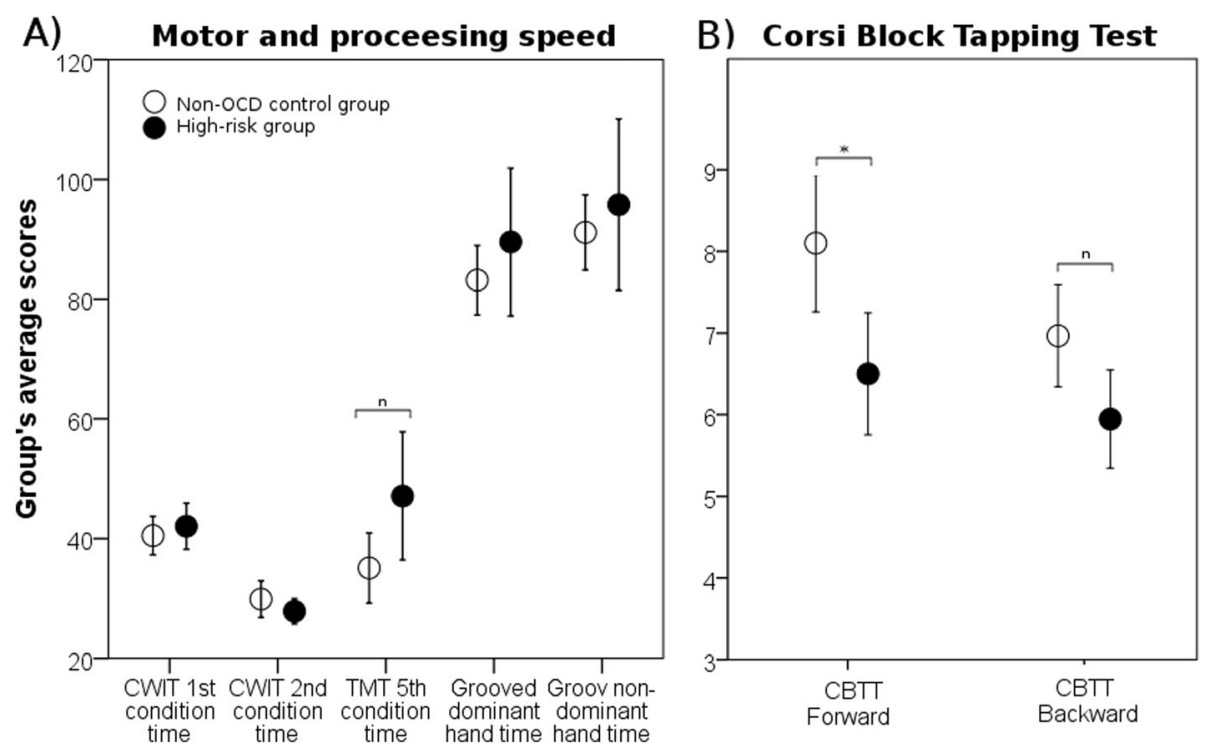

Fig. 1 Groups' average scores for a) the motor and processing speed MANOVA (higher punctuation means worse performance), and b) total IQ and IQ discrepancy (the difference between verbal IQ and performance IQ). Error bars means a 95\% confidence interval (CI). OCD - obsessivecompulsive disorder; CWIT - Color-Word Interference Test; TMT - Trail Making Test; CBTT - Corsi Block Tapping Test. ${ }^{n} p$-value $<0.05$ (nominal significance); * $p$-value $<0.0055$ (Bonferroni corrected)

processing speed have been found in adult patients with schizophrenia and comorbid OCD [69] or OCS [70], suggesting that such impairments may constitute a broader vulnerability marker for related psychiatric disorders.

The cognitive subdomain analysis revealed significant underperformance in spatial (nonverbal) working memory, as measured by the Corsi Block Tapping Test in the pediatric participants at $\mathrm{HR}$ for $\mathrm{OCD}$, in comparison to NOC. Associations between pediatric OCD and impairments in nonverbal memory have been inconsistently reported [30-32, 71, 72]. Likewise, the only study, to our knowledge, which investigated neuropsychological dysfunction among pediatric FDRs of patients with OCD found no impairments in spatial working memory [34]. Nonetheless, accumulating evidence supports the

Table 4 Difference Within Neurocognitive Domains

\begin{tabular}{llll}
\hline Neuropsychological measure & $F$ & Df & $p$-value MANOVA \\
\hline Estimated intellectual efficiency & 2.085 & 4 & 0.099 \\
Attention & 0.718 & 7 & 0.657 \\
Motor and processing speed & 3.115 & 5 & $0.019^{\text {n }}$ \\
Visuoconstructive abilities & 1.868 & 2 & 0.166 \\
Visuospatial memory & 2.787 & 3 & 0.051 \\
Verbal memory & 0.679 & 3 & 0.570 \\
Working memory & 3.046 & 2 & 0.057 \\
Cognitive flexibility & 2.362 & 5 & 0.057 \\
Inhibitory control & 0.325 & 4 & 0.859 \\
\hline
\end{tabular}

MANOVA - multivariate analysis of variance; Df - Degree of Freedom; ${ }^{\mathrm{n}} p$ value $<0.05$ (nominal significance) association between deficits in nonverbal memory and adult OCD [55, 73-82]. Indeed, comprehensive metaanalyses revealed significant associations between deficits in nonverbal memory and adult $\mathrm{OCD}[19,83]$. Moreover, a recent meta-analysis indicated that adult FDRs of patients with OCD exhibit impairments in short-term visuospatial memory [84].

Moreover, the cognitive subdomains analysis revealed a nominally significant discrepancy between higher verbal and lower performance IQ scores among pediatric participants at HR for OCD, as compared to NOC. Supporting the impairment in processing speed detected in the cognitive domain analysis, a nominally significant difference between groups was found in the time to complete the fifth condition of the Trail Making Test. In accordance with these findings, a recent study identified a significant discrepancy between higher verbal and lower performance IQ scores in pediatric OCD patients, as compared to pediatric healthy developing individuals [89]. Those findings are consistent with a recent metaanalysis indicating a discrepancy between higher verbal and lower performance IQ scores in adult patients with OCD [18], which could be explained by their poorer processing speed negatively affecting the performance IQ scores $[18,85,86]$. Previous investigations have indicated that such discrepancy is associated with reduced motor competence among preschoolers [87] and functional neuroimaging-detected alterations during cognitive conflict resolution among children and adolescents [88]. In this regard, the appropriate school environment has reportedly contributed to improvements in the 
Table 5 Mean, standard deviation, range and between-groups comparison of neuropsychological variables

\begin{tabular}{|c|c|c|c|c|c|c|}
\hline \multirow[b]{2}{*}{ Neuropsychological measure } & \multicolumn{2}{|c|}{$\begin{array}{l}\text { High Risk } \\
\mathrm{n}=18\end{array}$} & \multicolumn{2}{|c|}{$\begin{array}{l}\text { Non-OCD Control } \\
n=31\end{array}$} & \multirow[b]{2}{*}{$t$-test } & \multirow[b]{2}{*}{$p$-value } \\
\hline & Mean & $(\mathrm{SD})$ & Mean & $(\mathrm{SD})$ & & \\
\hline \multicolumn{7}{|l|}{$\mathrm{IQ}$} \\
\hline Total (WASI) & 103.5 & $(12.2)$ & 105.6 & $(13.4)$ & 0.07 & 0.938 \\
\hline Verbal (WASI) & 112.5 & $(15.2)$ & 110.5 & $(15.4)$ & 1.02 & 0.313 \\
\hline Performance (WASI) & 93.9 & $(9.8)$ & 99.7 & $(10.1)$ & -1.28 & 0.207 \\
\hline Verbal-Performance Discrepancy ${ }^{a}$ & 18.61 & $(13.2)$ & 10.8 & $(11.6)$ & 2.11 & $0.043^{n}$ \\
\hline \multicolumn{7}{|l|}{ ATTENTION } \\
\hline RAVLT span A & 6.2 & $(1.5)$ & 6.4 & $(1.6)$ & -0.49 & 0.622 \\
\hline RAVLT span B & 5.7 & $(1.9)$ & 5.6 & $(1.5)$ & 0.19 & 0.843 \\
\hline TMT 1st condition omissions & 0.2 & $(0.7)$ & 0.2 & $(0.4)$ & -0.08 & 0.936 \\
\hline TMT 4th condition sequence errors & 0.4 & $(1.0)$ & 0.4 & $(0.6)$ & -0.15 & 0.879 \\
\hline DFT 1 e DFT 2 - \%errors & .12 & $(0.2)$ & .04 & $(0.1)$ & 1.47 & 0.152 \\
\hline WCST failures to maintain set & 1.1 & $(1.2)$ & 1.2 & $(1.0)$ & -0.30 & 0.764 \\
\hline Go-NoGo omissions & 3.6 & $(6.5)$ & 2.6 & $(4.0)$ & 0.78 & 0.439 \\
\hline \multicolumn{7}{|l|}{ MOTOR AND PROCESSING SPEED } \\
\hline CWIT color naming time & 42.1 & $(7.8)$ & 39.9 & $(9.1)$ & 0.86 & 0.390 \\
\hline CWIT word reading time & 27.8 & $(4.3)$ & 28.9 & $(7.4)$ & -0.67 & 0.503 \\
\hline TMT 5th condition time & 47.1 & $(21.5)$ & 34.0 & $(14.4)$ & 2.27 & $0.030^{n}$ \\
\hline Grooved dominant hand time & 89.5 & $(24.9)$ & 83.7 & $(15.0)$ & 0.90 & 0.376 \\
\hline Grooved non-dominant hand time & 95.8 & $(28.9)$ & 92.4 & $(19.0)$ & 0.44 & 0.662 \\
\hline \multicolumn{7}{|l|}{ VISUOCONSTRUCTIVE ABILITIES } \\
\hline Block Design Test & 19.0 & $(9.5)$ & 25.6 & $(12.4)$ & -2.08 & $0.042^{n}$ \\
\hline ROCF total score - copy & 28.8 & $(6.5)$ & 30.5 & $(3.7)$ & -0.59 & 0.558 \\
\hline \multicolumn{7}{|l|}{ VISUOSPATIAL MEMORY } \\
\hline CBTT forward hits & 6.5 & $(1.5)$ & 8.1 & $(2.3)$ & -2.94 & $0.005^{*}$ \\
\hline ROCF immediate recall & 18.7 & $(6.7)$ & 19.2 & $(5.4)$ & -0.26 & 0.792 \\
\hline ROCF delayed recall & 18.3 & $(6.8)$ & 18.4 & $(5.6)$ & -0.08 & 0.930 \\
\hline \multicolumn{7}{|l|}{ VERBAL MEMORY } \\
\hline DST forward hits & 7.5 & $(1.3)$ & 7.0 & $(2.1)$ & 1.15 & 0.254 \\
\hline RAVLT immediate recall & 9.9 & $(2.2)$ & 10.3 & $(2.6)$ & -0.55 & 0.583 \\
\hline RAVLT delayed recall & 9.9 & $(2.3)$ & 10.3 & $(2.9)$ & -0.21 & 0.828 \\
\hline \multicolumn{7}{|l|}{ WORKING MEMORY } \\
\hline CBTT backward hits & 5.9 & $(1.2)$ & 7.0 & $(1.7)$ & -2.31 & $0.026^{n}$ \\
\hline DST backward hits & 4.8 & $(1.7)$ & 4.7 & $(1.7)$ & 0.25 & 0.797 \\
\hline \multicolumn{7}{|l|}{ COGNITIVE FLEXIBILITY } \\
\hline WCST Perseverative errors & 10.4 & $(3.5)$ & 9.8 & $(3.8)$ & 0.46 & 0.642 \\
\hline WCST categories & 2.4 & $(1.2)$ & 2.5 & $(1.2)$ & -0.10 & 0.913 \\
\hline DFT \%Perseverative errors & .13 & $(0.2)$ & .03 & $(0.1)$ & 0.74 & 0.464 \\
\hline TMT 4-5 & 96.2 & $(86.3)$ & 84.3 & $(50.6)$ & 0.15 & 0.877 \\
\hline Brixton hits & 36.6 & $(8.5)$ & 40.0 & $(4.1)$ & -1.16 & 0.254 \\
\hline \multicolumn{7}{|l|}{ INHIBITORY CONTROL } \\
\hline Go-NoGo Commission errors & 8.8 & (3.9) & 8.5 & $(3.7)$ & 0.25 & 0.800 \\
\hline CWIT 3 errors & 2.8 & (3.5) & 2.0 & $(2.8)$ & 0.64 & 0.525 \\
\hline
\end{tabular}


Table 5 Mean, standard deviation, range and between-groups comparison of neuropsychological variables (Continued)

\begin{tabular}{|c|c|c|c|c|c|c|}
\hline \multirow[b]{2}{*}{ Neuropsychological measure } & \multicolumn{2}{|c|}{$\begin{array}{l}\text { High Risk } \\
n=18\end{array}$} & \multicolumn{2}{|c|}{$\begin{array}{l}\text { Non-OCD Control } \\
\mathrm{n}=31\end{array}$} & \multirow[b]{2}{*}{ t-test } & \multirow[b]{2}{*}{$p$-value } \\
\hline & Mean & (SD) & Mean & $(\mathrm{SD})$ & & \\
\hline CWIT 4 errors & 2.0 & $(2.2)$ & 2.5 & (3.4) & -0.17 & 0.863 \\
\hline CWIT 3-1 time difference & 39.1 & $(18.8)$ & 36.5 & $(18.0)$ & 0.37 & 0.709 \\
\hline
\end{tabular}

${ }^{a}$ The Verbal - Performance difference is calculated by subtracting the performance IQ from the verbal IQ. WASI - Wechsler abbreviated scale of intelligence; RAVLT - Rey auditory verbal learning test; TMT - Trail making test; DFT- Design fluency test; WCST - Wisconsin card sorting test; CWIT - Color-word interference test; ROCF - Rey-Osterrieth complex figure; CBTT - Corsi block-tapping test; DST - Digit span test. ${ }^{n} p$-value $<0.05$ (nominal significance); ${ }^{*} p$-value $<0.0055$ (according to Bonferroni correction)

discrepancy between verbal and performance IQ scores [90] (Lapierre et al., 1992). Further investigations are warranted to confirm this discrepancy in children and adolescents at HR for OCD, which could foster early interventions in the course of the disease.

The major limitation of the current study is the small sample size, which limits the detection of significant differences between the groups. Therefore, the reported findings should be considered preliminary, requiring further confirmation in larger samples. Nonetheless, the present study has raised pertinent hypotheses that are well integrated into the existing literature on the topic. Indeed, one longitudinal study reported that impairments in motor and visuospatial skills predict the maintenance of OCD from childhood into adulthood [91].

\section{Conclusions}

In summary, this neuropsychological study of children and adolescents at HR for OCD identified impairments in spatial working memory and trend in significance for impairment in motor and processing speed when compared to NOC. Future longitudinal studies following children at $\mathrm{HR}$ for $\mathrm{OCD}$ are required to investigate cognitive dysfunction as a vulnerability marker for the disorder, which may enhance the prevention of OCD among children and adolescents.

\section{Supplementary information}

Supplementary information accompanies this paper at https://doi.org/10. 1186/s12888-020-02751-5.

Additional file 1: Figure S1. Flow chart - design and recruitment of

High Risk and non-OCD controls.

\footnotetext{
Abbreviations

CBTT: Corsi block-tapping task; DSM-IV: Diagnostic and Statistical Manual of Mental Disorder Fourth Edition; DST: Digit span test; EF: Executive function; FDRs: First-degree relatives; FSIQ: Full-Scale Intelligence Quotient; HR: Highrisk; IQ: Intelligence Quotient; K-SADS-PL: Kiddie Schedule For Affective Disorders And Schizophrenia for School Aged-Children; MANOVA: Multivariate Analysis of Variance; NOC: Non-OCD controls; OC: Obsessive-compulsive; OCD: Obsessive-compulsive disorder; OCS: Obsessive-compulsive symptoms; PIQ: Performance Intelligence Quotient; SCID-I/P: Structured Clinical Interview for DSM-IV-TR Axis I Disorders, Patient Edition.; TMT: Trail making test; VIQ: Verbal Intelligence Quotient; Y-BOCS: Yale-Brown Obsessive-Compulsive Scale
}

Acknowledgments

We thank Dr. Sonia Borcato and Dr. Joana Balardin for their assistance in the data collection.

\section{Authors' contributions}

All authors have read and approved the manuscript. ETB has made substantial contributions to the conception of the work; analysis, and interpretation of data; has drafted the work and approved the submitted version (and any substantially modified version that involves the author's contribution to the study); and has agreed both to be personally accountable for the author's own contributions and to ensure that questions related to the accuracy or integrity of any part of the work, even ones in which the author was not personally involved, are appropriately investigated, resolved, and the resolution documented in the literature. LS has made substantial contributions to the analysis and interpretation of data; has reviewed the work and approved the submitted version (and any substantially modified version that involves the author's contribution to the study); and has agreed both to be personally accountable for the author's own contributions and to ensure that questions related to the accuracy or integrity of any part of the work, even ones in which the author was not personally involved, are appropriately investigated, resolved, and the resolution documented in the literature. MMS has contributed collecting the data and revising the work; has approved the submitted version (and any substantially modified version that involves the author's contribution to the study); and has agreed both to be personally accountable for the author's own contributions and to ensure that questions related to the accuracy or integrity of any part of the work, even ones in which the author was not personally involved, are appropriately investigated, resolved, and the resolution documented in the literature. $\mathrm{MQH}$ has substantively revised the work and approved the submitted version (and any substantially modified version that involves the author's contribution to the study); and has agreed both to be personally accountable for the author's own contributions and to ensure that questions related to the accuracy or integrity of any part of the work, even ones in which the author was not personally involved, are appropriately investigated, resolved, and the resolution documented in the literature. PC has made substantial contributions to the conception of the work and approved the submitted version (and any substantially modified version that involves the author's contribution to the study); and has agreed both to be personally accountable for the author's own contributions and to ensure that questions related to the accuracy or integrity of any part of the work, even ones in which the author was not personally involved, are appropriately investigated, resolved, and the resolution documented in the literature. GR has made substantial contributions to the analysis of data and approved the submitted version (and any substantially modified version that involves the author's contribution to the study); and has agreed both to be personally accountable for the author's own contributions and to ensure that questions related to the accuracy or integrity of any part of the work, even ones in which the author was not personally involved, are appropriately investigated, resolved, and the resolution documented in the literature. ECM has substantively revised the work and approved the submitted version (and any substantially modified version that involves the author's contribution to the study); and has agreed both to be personally accountable for the author's own contributions and to ensure that questions related to the accuracy or integrity of any part of the work, even ones in which the author was not personally involved, are appropriately investigated, resolved, and the resolution documented in the literature. RGS has substantively revised the work and approved the submitted version (and any substantially modified version that involves the author's contribution to the 
study); and has agreed both to be personally accountable for the author's own contributions and to ensure that questions related to the accuracy or integrity of any part of the work, even ones in which the author was not personally involved, are appropriately investigated, resolved, and the resolution documented in the literature. GVP has substantively revised the work and approved the submitted version (and any substantially modified version that involves the author's contribution to the study); and has agreed both to be personally accountable for the author's own contributions and to ensure that questions related to the accuracy or integrity of any part of the work, even ones in which the author was not personally involved, are appropriately investigated, resolved, and the resolution documented in the literature. CC have substantively revised the work and approved the submitted version (and any substantially modified version that involves the author's contribution to the study); and has agreed both to be personally accountable for the author's own contributions and to ensure that questions related to the accuracy or integrity of any part of the work, even ones in which the author was not personally involved, are appropriately investigated, resolved, and the resolution documented in the literature. MCB has made substantial contributions to the conception of the work, analysis, and interpretation of data; has drafted the work and approved the submitted version (and any substantially modified version that involves the author's contribution to the study); and has agreed both to be personally accountable for the author's own contributions and to ensure that questions related to the accuracy or integrity of any part of the work, even ones in which the author was not personally involved, are appropriately investigated, resolved, and the resolution documented in the literature.

\section{Funding}

Financial support was provided by Sao Paulo Research Foundation (FAPESP Fundação de Amparo à Pesquisa do Estado de São Paulo) grants \#2016/ 05865-8 to Dr. Batistuzzo and \#2016/04595-7 to Dr. Souza; and by the Coordination for the Improvement of Higher Level Personnel (CAPES, Coordenação de Aperfeiçoamento de Pessoal de Nível Superior) PROEX (Programa de Exelência Acadêmica) fellowship to Dr. Bernardes. All these financial supports were provided to the researchers for planning the design of the study, data collection and analysis, interpretation and in writing the manuscript. Also more, the National Council for Scientific and Technological Development (CNPq, Conselho Nacional de Desenvolvimento Científico e Tecnológico) was provided to the National Institute of Developmental Psychiatry for Children and Adolescents (INPD, Instituto Nacional de Psiquiatria do Desenvolvimento para Crianças e Adolescentes, \#573974/2008-0), Sao Paulo, Brazil, allowing the payment of mental health professionals during the data collection.

\section{Availability of data and materials}

The datasets analyzed during the current study are available from the corresponding author on reasonable request.

\section{Ethics approval and consent to participate}

This study was approved by the local Medical Ethics Committee of Faculdade de Medicina, Universidade de Sao Paulo (FMUSP), and all participants and parents/legal guardians gave their written informed consent after having been enlightened the details of the procedure.

\section{Consent for publication}

Not applicable.

\section{Competing interests}

Dr. Polanczyk has served as a speaker and/or consultant to Shire, Teva, and Johnson \& Johnson; has developed educational material for Janssen-Cilag and Shire. All the remaining authors report no biomedical financial interests or potential conflicts of interest.

\section{Author details}

${ }^{1}$ Departamento de Psiquiatria, Hospital das Clinicas HCFMUSP, Faculdade de Medicina, Universidade de Sao Paulo, R. Dr Ovidio Pires de Campos, 875, Sao Paulo, SP, Brazil. ${ }^{2}$ Instituto de Ciencias Exatas e Tecnologicas da Universidade Federal de Vicosa, Viçosa, Brazil. ${ }^{3}$ Curso de Psicologia, Faculdade de Ciências Humanas e da Saúde, Pontifícia Universidade Católica de São Paulo, Sao Paulo, SP, Brazil.
Received: 6 June 2019 Accepted: 23 June 2020

Published online: 20 July 2020

\section{References}

1. Association AP. The Diagnostic and Statistical Manual of Mental Disorders (DMS-V). 2013

2. Fontenelle LF, Mendlowicz MV, Versiani M. The descriptive epidemiology of obsessive-compulsive disorder. Prog Neuro-Psychopharmacol Biol Psychiatry. 2006;30(3):327-37.

3. Ruscio AM, Stein DJ, Chiu WT, Kessler RC. The epidemiology of obsessivecompulsive disorder in the National Comorbidity Survey Replication. Mol Psychiatry. 2010;15(1):53-63.

4. Taylor S. Early versus late onset obsessive-compulsive disorder: evidence for distinct subtypes. Clin Psychol Rev. 2011;31(7):1083-100.

5. Geller DA. Obsessive-compulsive and spectrum disorders in children and adolescents. Psychiatr Clin North Am. 2006;29(2):353-70.

6. Hirschtritt ME, Bloch MH, Mathews CA. Obsessive-compulsive disorder: advances in diagnosis and treatment. Jama. 2017;317(13):1358-67.

7. Dougherty DD, Brennan BP, Stewart SE, Wilhelm S, Widge AS, Rauch SL. Neuroscientifically informed formulation and treatment planning for patients with obsessive-compulsive disorder: a review. JAMA Psychiatry. 2018;75(10):1081-7.

8. Bloch $\mathrm{MH}$, Storch EA. Assessment and management of treatment-refractory obsessive-compulsive disorder in children. J Am Acad Child Adolesc Psychiatry. 2015;54(4):251-62.

9. Pallanti S, Quercioli L. Treatment-refractory obsessive-compulsive disorder: methodological issues, operational definitions and therapeutic lines. Prog Neuro-Psychopharmacol Biol Psychiatry. 2006;30(3):400-12.

10. Eisen JL, Sibrava NJ, Boisseau CL, Mancebo MC, Stout RL, Pinto A, et al. Fiveyear course of obsessive-compulsive disorder: predictors of remission and relapse. J Clin Psychiatry. 2013;74(3):233-9.

11. Pauls DL, Abramovitch A, Rauch SL, Geller DA. Obsessive-compulsive disorder: an integrative genetic and neurobiological perspective. Nat Rev Neurosci. 2014;15(6):410-24.

12. Pauls DL, Alsobrook JP 2nd, Goodman W, Rasmussen S, Leckman JF. A family study of obsessive-compulsive disorder. Am J Psychiatry. 1995;152(1): 76-84.

13. Mataix-Cols D, Boman M, Monzani B, Rück C, Serlachius E, Långström N, et al. Population-based, multigenerational family clustering study of obsessive-compulsive disorder. JAMA Psychiatry. 2013;70(7):709-17.

14. Chacon P, Bernardes E, Faggian L, Batistuzzo M, Moriyama T, Miguel EC, et al. Obsessive-compulsive symptoms in children with first degree relatives diagnosed with obsessive-compulsive disorder. Braz J Psychiatry. 2018;40(4): 388-93.

15. Smit DJA, Cath D, Zilhão NR, et al. Genetic meta-analysis of obsessivecompulsive disorder and self-report compulsive symptoms. Am J Med Genet B Neuropsychiatr Genet. 2020;183(4):208-216. https://doi.org/10.1002/ ajmg.b.32777.

16. Black DW, Gaffney GR. Subclinical obsessive-compulsive disorder in children and adolescents: additional results from a "high-risk" study. CNS Spectr. 2008;13(9 Suppl 14):54-61.

17. Hezel DM, McNally RJ. A Theoretical review of cognitive biases and deficits in obsessive-compulsive disorder. Biol Psychol. 2016;121(Pt B):221-32.

18. Abramovitch A, Anholt G, Raveh-Gottfried S, Hamo N, Abramowitz JS. Metaanalysis of intelligence quotient $(\mathrm{IQ})$ in obsessive-compulsive disorder. Neuropsychol Rev. 2018;28(1):111-20.

19. Shin NY, Lee TY, Kim E, Kwon JS. Cognitive functioning in obsessivecompulsive disorder: a meta-analysis. Psychol Med. 2014;44(6):1121-30.

20. Cavedini P, Zorzi C, Piccinni M, Cavallini MC, Bellodi L. Executive dysfunctions in obsessive-compulsive patients and unaffected relatives: searching for a new intermediate phenotype. Biol Psychiatry. 2010;67(12): 1178-84.

21. Chamberlain SR, Fineberg NA, Menzies LA, Blackwell AD, Bullmore ET, Robbins TW, et al. Impaired cognitive flexibility and motor inhibition in unaffected first-degree relatives of patients with obsessive-compulsive disorder. Am J Psychiatry. 2007;164(2):335-8.

22. Menzies L, Achard S, Chamberlain SR, Fineberg N, Chen CH, del Campo N, et al. Neurocognitive endophenotypes of obsessive-compulsive disorder. Brain. 2007;130(Pt 12):3223-36.

23. Viswanath B, Janardhan Reddy YC, Kumar KJ, Kandavel T, Chandrashekar CR. Cognitive endophenotypes in OCD: a study of unaffected siblings of 
probands with familial OCD. Prog Neuro-Psychopharmacol Biol Psychiatry. 2009:33(4):610-5.

24. Lochner C, Chamberlain SR, Kidd M, Fineberg NA, Stein DJ. Altered cognitive response to serotonin challenge as a candidate endophenotype for obsessivecompulsive disorder. Psychopharmacology. 2016;233(5):883-91.

25. Li B, Sun JH, Li T, Yang YC. Neuropsychological study of patients with obsessive-compulsive disorder and their parents in China: searching for potential endophenotypes. Neurosci Bull. 2012;28(5):475-82.

26. Delorme R, Gousse V, Roy I, Trandafir A, Mathieu F, Mouren-Simeoni MC, et al. Shared executive dysfunctions in unaffected relatives of patients with autism and obsessive-compulsive disorder. Eur Psychiatry. 2007;22(1):32-8.

27. Ozcan H, Ozer S, Yagcioglu S. Neuropsychological, electrophysiological and neurological impairments in patients with obsessive compulsive disorder, their healthy siblings and healthy controls: identifying potential endophenotype(s). Psychiatry Res. 2016;240:110-7.

28. do Rosario-Campos MC, Leckman JF, Curi M, Quatrano S, Katsovitch L, Miguel EC, et al. A family study of early-onset obsessive-compulsive disorder. Am J Med Genet B Neuropsychiatr Genet. 2005;136B(1):92-7.

29. Zhang J, Yang X, Yang Q. Neuropsychological dysfunction in adults with early-onset obsessive-compulsive disorder: the search for a cognitive endophenotype. Braz J Psychiatry. 2015;37(2):126-32.

30. Geller DA, Abramovitch A, Mittelman A, Stark A, Ramsey K, Cooperman A, et al. Neurocognitive function in paediatric obsessive-compulsive disorder. World J Biol Psychiatry. 2018;19(2):142-51.

31. Abramovitch A, Abramowitz JS, Mittelman A, Stark A, Ramsey K, Geller DA. Research review: neuropsychological test performance in pediatric obsessive-compulsive disorder--a meta-analysis. J Child Psychol Psychiatry. 2015;56(8):837-47.

32. Andres $S$, Boget $T$, Lazaro L, Penades R, Morer A, Salamero M, et al. Neuropsychological performance in children and adolescents with obsessive-compulsive disorder and influence of clinical variables. Biol Psychiatry. 2007:61(8):946-51.

33. Ornstein TJ, Arnold P, Manassis K, Mendlowitz S, Schachar R. Neuropsychological performance in childhood OCD: a preliminary study. Depress Anxiety. 2010;27(4):372-80.

34. Negreiros J, Belschner L, Best JR, Lin S, Franco Yamin D, Joffres Y, et al. Neurocognitive risk markers in pediatric obsessive-compulsive disorder. J Child Psychol Psychiatry. 2020;61(5):605-13.

35. Hamo N, Abramovitch A, Zohar A. A computerized neuropsychological evaluation of cognitive functions in a subclinical obsessive-compulsive sample. J Behav Ther Exp Psychiatry. 2018;59:142-9.

36. Johansen T, Dittrich WH. Cognitive performance in a subclinical obsessivecompulsive sample 1: cognitive functions. Psychiatry J. 2013;2013:565191.

37. Pietrefesa AS, Evans DW. Affective and neuropsychological correlates of children's rituals and compulsive-like behaviors: continuities and discontinuities with obsessive-compulsive disorder. Brain Cogn. 2007;65(1):36-46.

38. Fatori D, de Braganca Pereira CA, Asbahr FR, Requena G, Alvarenga PG, de Mathis MA, et al. Adaptive treatment strategies for children and adolescents with obsessive-compulsive disorder: a sequential multiple assignment randomized trial. J Anxiety Disord. 2018;58:42-50.

39. First MB, Gibbon M. The structured clinical interview for DSM-IV axis I disorders (SCID-I) and the structured clinical interview for DSM-IV axis I| disorders (SCID-1I); 2004.

40. Kaufman J, Birmaher B, Brent D, Rao U, Flynn C, Moreci P, et al. Schedule for affective disorders and schizophrenia for school-age children-present and lifetime version (K-SADS-PL): initial reliability and validity data. J Am Acad Child Adolesc Psychiatry. 1997;36(7):980-8.

41. Goodman WK, Price LH, Rasmussen SA, Mazure C, Fleischmann RL, Hill CL, et al. The Yale-Brown obsessive compulsive scale. I. Development, use, and reliability. Arch Gen Psychiatry. 1989;46(11):1006-11.

42. Petersen AC, Crockett L, Richards M, Boxer A. A self-report measure of pubertal status: reliability, validity, and initial norms. J Youth Adolesc. 1988; 17(2):117-33.

43. Oldfield RC. The assessment and analysis of handedness: the Edinburgh inventory. Neuropsychologia. 1971;9(1):97-113.

44. Wechsler D. Wechsler abbreviated scale of intelligence (WASI). San Antonio: The Psychological Corporation; 1999.

45. Trentini CM, Yates DB, Heck VS. Escala de Inteligência Wechsler Abreviada (WASI): Manual profissional. São Paulo: Casa do Psicologo; 2014.

46. Rey A. L'examen clinique en psychologie. Paris: Pressess Universitaires de France; 1958.
47. Delis D, Kaplan E, Kramer J. Delis-Kaplan executive function system (D-KEFS). Can J Sch Psychol. 2001;20:117-28. https://doi.org/10.1177/ 0829573506295469.

48. Heaton RK, Chelune GJ, Talley JL, Kay GG, Curtiss G. Wisconsin card sorting test manual. Odessa: PAR; 1993.

49. Nosek BA, Banaji MR. The go/no-go association task. Soc Cogn. 2001. https://doi.org/10.1521/soco.19.6.625.20886.

50. Matthews CG, Klove K. Instruction manual for the adult neuropsychology test battery. Madison: University of Wisconsin Medical; 1964.

51. Osterrieth PA. Le test de copie d'une figure complexe. Arch Psychol. 1944; 30:206-356.

52. Wechsler D. Manual for Wechsler memory scale - revised. San Antonio: The Psychological Corporation; 1987.

53. Wechsler D. Wechsler intelligence scale for children-third edition. San Antonio: TX Psychol Corp; 1991.

54. Burgess PW, Shallice T. The Hayling and Brixton tests. Thurston, Suffolk: Thames Valley Test Company Limited; 1997. p. 2-4.

55. Purcell R, Maruff $P$, Kyrios M, Pantelis C. Cognitive deficits in obsessivecompulsive disorder on tests of frontal-striatal function. Biol Psychiatry. 1998;43(5):348-57. https://doi.org/10.1016/s0006-3223(97)00201-1.

56. Rampacher F, Lennertz L, Vogeley A, Schulze-Rauschenbach S, Kathmann N, Falkai $P$, et al. Evidence for specific cognitive deficits in visual information processing in patients with OCD compared to patients with unipolar depression. Prog Neuro-Psychopharmacol Biol Psychiatry. 2010;34(6):984-91.

57. Kuelz AK, Hohagen F, Voderholzer U. Neuropsychological performance in obsessive-compulsive disorder: a critical review. Biol Psychol. 2004;65(3):185236.

58. Christian CJ, Lencz T, Robinson DG, Burdick KE, Ashtari M, Malhotra AK, et al. Gray matter structural alterations in obsessive-compulsive disorder: relationship to neuropsychological functions. Psychiatry Res. 2008;164(2): 123-31.

59. Lennertz L, Rampacher F, Vogeley A, Schulze-Rauschenbach S, Pukrop R Ruhrmann $S$, et al. Antisaccade performance in patients with obsessivecompulsive disorder and unaffected relatives: further evidence for impaired response inhibition as a candidate endophenotype. Eur Arch Psychiatry Clin Neurosci. 2012;262(7):625-34.

60. Burdick KE, Robinson DG, Malhotra AK, Szeszko PR. Neurocognitive profile analysis in obsessive-compulsive disorder. J Int Neuropsychol Soc. 2008; 14(4):640-5

61. Leopold R, Backenstrass M. Neuropsychological differences between obsessive-compulsive washers and checkers: a systematic review and metaanalysis. J Anxiety Disord. 2015;30:48-58.

62. McGuire JF, Crawford EA, Park JM, Storch EA, Murphy TK, Larson MJ, et al. Neuropsychological performance across symptom dimensions in pediatric obsessive compulsive disorder. Depress Anxiety. 2014;31(12):988-96.

63. Andres S, Lazaro L, Salamero M, Boget T, Penades R, Castro-Fornieles J. Changes in cognitive dysfunction in children and adolescents with obsessive-compulsive disorder after treatment. J Psychiatr Res. 2008;42(6): 507-14.

64. Choudhury TK, Davidson JE, Viswanathan A, Strutt AM. Deep brain stimulation of the anterior limb of the internal capsule for treatment of therapy-refractory obsessive compulsive disorder (OCD): a case study highlighting neurocognitive and psychiatric changes. Neurocase. 2017;23(2): $138-45$.

65. Jahangard L, Haghighi M, Shyayganfard M, Ahmadpanah M, Sadeghi Bahmani D, Bajoghli $H$, et al. Repetitive Transcranial magnetic stimulation improved symptoms of obsessive-compulsive disorder, but also cognitive performance: results from a randomized clinical trial with a cross-over Design and sham condition. Neuropsychobiology. 2016;73(4):224-32.

66. Mandali A, Weidacker K, Kim SG, Voon V. The ease and sureness of a decision: evidence accumulation of conflict and uncertainty. Brain. 2019; 142(5):1471-82.

67. Krueger RF, Eaton NR. Transdiagnostic factors of mental disorders. World Psychiatry. 2015;14(1):27-9.

68. Fusar-Poli P, Solmi M, Brondino N, Davies C, Chae C, Politi P, et al. Transdiagnostic psychiatry: a systematic review. World Psychiatry. 2019;18(2):192-207.

69. Sahoo S, Grover S, Nehra R. Comparison of neurocognitive domains in patients with schizophrenia with and without co-morbid obsessive compulsive disorder. Schizophr Res. 2018;201:151-8.

70. Michalopoulou PG, Konstantakopoulos G, Typaldou M, Papageorgiou C, Christodoulou GN, Lykouras L, et al. Can cognitive deficits differentiate 
between schizophrenia with and without obsessive-compulsive symptoms? Compr Psychiatry. 2014;55(4):1015-21.

71. Lewin AB, Larson MJ, Park JM, McGuire JF, Murphy TK, Storch EA. Neuropsychological functioning in youth with obsessive compulsive disorder: an examination of executive function and memory impairment. Psychiatry Res. 2014;216(1):108-15.

72. Kim KL, Christensen RE, Ruggieri A, Schettini E, Freeman JB, Garcia AM, et al. Cognitive performance of youth with primary generalized anxiety disorder versus primary obsessive-compulsive disorder. Depress Anxiety. 2019;36(2): $130-40$.

73. Rao NP, Reddy YC, Kumar KI, Kandavel T, Chandrashekar CR. Are neuropsychological deficits trait markers in OCD? Prog NeuroPsychopharmacol Biol Psychiatry. 2008;32(6):1574-9.

74. Nakao T, Okada K, Kanba S. Neurobiological model of obsessive-compulsive disorder: evidence from recent neuropsychological and neuroimaging findings. Psychiatry Clin Neurosci. 2014;68(8):587-605.

75. Segalas C, Alonso P, Labad J, Jaurrieta N, Real E, Jimenez S, et al. Verbal and nonverbal memory processing in patients with obsessive-compulsive disorder: its relationship to clinical variables. Neuropsychology. 2008;22(2): 262-72.

76. Cha KR, Koo MS, Kim CH, Kim JW, Oh WJ, Suh HS, et al. Nonverbal memory dysfunction in obsessive-compulsive disorder patients with checking compulsions. Depress Anxiety. 2008;25(11):E115-20.

77. Jang JH, Kim HS, Ha TH, Shin NY, Kang DH, Choi JS, et al. Nonverbal memory and organizational dysfunctions are related with distinct symptom dimensions in obsessive-compulsive disorder. Psychiatry Res. 2010;180(2-3): 93-8.

78. Savage CR, Keuthen NJ, Jenike MA, Brown HD, Baer L, Kendrick AD, et al. Recall and recognition memory in obsessive-compulsive disorder. J Neuropsychiatry Clin Neurosci. 1996;8(1):99-103.

79. Nakao T, Nakagawa A, Yoshiura T, Nakatani E, Nabeyama M, Sanematsu H, et al. Duration effect of obsessive-compulsive disorder on cognitive function: a functional MRI study. Depress Anxiety. 2009;26(9):814-23.

80. Zitterl W, Urban C, Linzmayer L, Aigner M, Demal U, Semler B, et al. Memory deficits in patients with DSM-IV obsessive-compulsive disorder. Psychopathology. 2001;34(3):113-7.

81. Martoni RM, Salgari G, Galimberti E, Cavallini MC, O'Neill J. Effects of gender and executive function on visuospatial working memory in adult obsessive-compulsive disorder. Eur Arch Psychiatry Clin Neurosci. 2015;265(8):707-18.

82. Batistuzzo MC, Hoexter MQ, Taub A, Gentil AF, Cesar RC, Joaquim MA, et al. Visuospatial memory improvement after gamma ventral Capsulotomy in treatment refractory obsessive-compulsive disorder patients. Neuropsychopharmacology. 2015;40(8):1837-45. https://doi.org/10.1038/ npp.2015.33.

83. Abramovitch A, Abramowitz JS, Mittelman A. The neuropsychology of adult obsessive-compulsive disorder: a meta-analysis. Clin Psychol Rev. 2013;33(8): 1163-71.

84. Zartaloudi E, Laws KR, Bramon E. Endophenotypes of executive functions in obsessive compulsive disorder? A meta-analysis in unaffected relatives. Psychiatr Genet. 2019;29(6):211-9.

85. Kluger A, Goldberg E. IQ patterns in affective disorder, lateralized and diffuse brain damage. J Clin Exp Neuropsychol. 1990;12(2):182-94.

86. Pernicano KM. Score differences in WAIS-R scatter for schizophrenics, depressives, and personality disorders: a preliminary analysis. Psychol Rep. 1986;59(2 Pt 1):539-43

87. Yu TY, Chen KL, Chou W, Yang SH, Kung SC, Lee YC, et al. Intelligence quotient discrepancy indicates levels of motor competence in preschool children at risk for developmental delays. Neuropsychiatr Dis Treat. 2016;12: $501-10$

88. Margolis AE, Davis KS, Pao LS, Lewis A, Yang X, Tau G, et al. Verbal-spatial IQ discrepancies impact brain activation associated with the resolution of cognitive conflict in children and adolescents. Dev Sci. 2018;21(2). https:// doi.org/10.1111/desc.12550.

89. Batistuzzo MC, Souza MM, Bernardes ET, Requena G, Miguel EC, Shavitt RG. Intelligence quotient $(\mathrm{IQ})$ in pediatric patients with obsessive-compulsive disorder. J Obsessive Compuls Relat Disord. 2020;26:100548.

90. Lapierre D, Braun CM, Le Pailleur L. A 54-point verbal-performance IQ discrepancy on the WISC-R: cognitive functioning of a child from an alternative school. Behav Neurol. 1992;5(2):97-106.
91. Bloch MH, Sukhodolsky DG, Dombrowski PA, Panza KE, Craiglow BG, Landeros-Weisenberger A, et al. Poor fine-motor and visuospatial skills predict persistence of pediatric-onset obsessive-compulsive disorder into adulthood. J Child Psychol Psychiatry. 2011;52(9):974-83.

\section{Publisher's Note}

Springer Nature remains neutral with regard to jurisdictional claims in published maps and institutional affiliations.

\section{Ready to submit your research? Choose BMC and benefit from:}

- fast, convenient online submission

- thorough peer review by experienced researchers in your field

- rapid publication on acceptance

- support for research data, including large and complex data types

- gold Open Access which fosters wider collaboration and increased citations

- maximum visibility for your research: over $100 \mathrm{M}$ website views per year

At BMC, research is always in progress.

Learn more biomedcentral.com/submissions 